${ }^{8}$ Harris WH, Salzmann EW, Athanasoulis CA, et al. Aspirin prophylaxis of venous thromboembolism after total hip replacement. $N$ Engl f Med $1977 ; 297: 1246-9$

${ }^{9}$ McKenna R, Bachmann F, Kaushal SP, Galante JO. Thromboembolic disease in patients undergoing total knee replacement. $\mathcal{f}$ Bone foint Surg 1976;58-A:928-32.

${ }^{10}$ McKenna R, Bachmann F, Whittaker B, Gilson JR, Weinberg M Jr. The hemostatic mechanism after open-heart surgery. II. Frequency of abnormal platelet function during and after extracorporeal circulation. 7 Thorac Cardiovasc Surg 1975;70:298-308.

11 Cox DR. Analysis of binary data. London: Chapman and Hall, 1970.

12 Nelder JA. Generalized linear interactive modelling (GLIM). Oxford: Numerical Analysis Group, 1977.

${ }^{13}$ Soreff J, Johnsson H, Diener L, Göransson L. Acetylsalicylic acid in a trial to diminish thromboembolic complications after elective hip surgery. Acta Orthop Scand 1975;46:246-55.

${ }^{14}$ Zekert F, Kohn P, Vormittag E, Poigenfürst J, Thien M. Thrombo- embolieprophylaxe mit Acetylsalicylsäure bei Operationen wegen hüftgelenksnaher Frakturen. Monatsschrift für Unfallheilkunde und Versicherungsmedizin $1974 ; 77: 97-110$.

15 Peterson J, Zucker MB. The effect of adenosine monophosphate, arcaine and anti-inflammatory agents on thrombosis and platelet function in rabbits. Thrombosis et Diathesis Haemorrhagica 1970;23:148-58.

16 Kelton JG, Hirsh J, Carter CJ, Buchanan MR. Thrombogenic effect of high-dose aspirin in rabbits. Relationship to inhibition of vessel wall synthesis of prostaglandin $I_{2}$-like activity. $\mathcal{F}$ Clin Invest 1978;62:892-5.

17 Cerskus AL, Ali M, McDonald JWD. Possible significance of functional platelets circulating between doses of aspirin. Blood 1978;52, suppl 1: 160.

18 Stanton JR, Freis ED, Wilkins RW. The acceleration of linear flow in the deep veins of the lower extremity of man by local compression. f Clin Invest $1949 ; 28: 553-8$

(Accepted 27 November 1979)

\title{
Increasing importance of plasmid-mediated trimethoprim resistance in enterobacteria: two six-month clinical surveys
}

\author{
K J TOWNER, N J PEARSON, PATRICIA A PINN, F O'GRADY
}

\section{Summary and conclusions}

All clinical isolates of enterobacteria received at the laboratory were monitored for trimethoprim resistance over six months in 1978. The survey was repeated in 1979 and the incidence of trimethoprim resistance showed a slight decrease, but the proportion of resistant strains owing their trimethoprim resistance to transferable $R$ plasmids had almost trebled. There was also a large increase in the proportion of resistant strains exhibiting high-level non-transferable trimethoprim resistance.

These findings suggest transposition of genes conferring trimethoprim resistance from plasmids to the bacterial chromosome.

\section{Introduction}

Trimethoprim combined with sulphamethoxazole (co-trimoxazole) has been used in Great Britain since 1969. During the first 10 years several different forms of trimethoprim resistance were reported. ${ }^{1-4}$ One of the original reasons for prescribing trimethoprim in combination with sulphamethoxazole was the assumption that the sulphonamide would exert appreciable control over the emergence of at least one form of resistance. Sulphonamide resistance, however, is common in many of the species responsible for infections often treated with cotrimoxazole, and there may be grounds for using trimethoprim alone for certain infections. ${ }^{5-7}$ If trimethoprim is to be released for use alone it will be important to monitor any effect of the separation on the incidence of resistance to trimethoprim.

We have reported on the emergence of trimethoprim resistance in patients treated with low doses of co-trimoxazole for prolonged periods. ${ }^{48}$ Such patients offer a particular opportunity to observe the extent to which treatment may be compromised by resistance but throw little light on the overall

\footnotetext{
Department of Microbiology, University Hospital, Queen's Medical Centre, Nottingham NG7 2UH

K J TOWNER, BSC, PHD, microbial geneticist

N J PEARSON, FIMLS, senior medical laboratory scientific officer PATRICIA A PINN, BSC, research student

F O'GRADY, FRCP, FRCPATH, professor of microbiology
}

prevalence of organisms exhibiting the various forms of trimethoprim resistance. To provide such information and establish a basis for observing any future changes in the incidence and types of trimethoprim resistance encountered clinically, we report the results of two six-month surveys' of enterobacteria isolated from clinical specimens during January to June 1978 and January to June 1979. In addition to testing for trimethoprim resistance, we also tested each resistant isolate $(a)$ for the presence of $\mathbf{R}$ plasmids conferring transferable trimethoprim resistance and $(b)$ for resistance to sulphonamides.

\section{Methods}

Trimethoprim-resistant bacteria-During the survey periods enterobacteria from all types of clinical specimens received at this laboratory were identified by standard laboratory techniques and their resistance to trimethoprim measured by multipoint inoculation (with a final inoculum of about 100 colony-forming units) on to plates of Oxoid DST agar containing $4 \%$ lysed horse blood plus doubling dilutions of trimethoprim lactate (Burroughs Wellcome). Repeat specimens from the same patient were excluded.

Transfer of trimethoprim resistance-Isolates resistant to $\geqslant 8 \mathrm{mg}$ trimethoprim/l were tested for their ability to transfer resistance to a standard genetically characterised strain of Escherichia coli, as described. ${ }^{8}$ In cases where transfer occurred single colonies were tested with antibiotic discs (Mast) to determine whether other resistances had been co-transferred. When transfer of several resistances had occurred the experiment was repeated, selecting for the transfer of each resistance independently. Transconjugants of each type were then tested to see whether the resistances were transferable separately - that is, on different plasmids-or always together-that is, on the same plasmid.

Resistance to sulphonamides-Isolates resistant to $\geqslant 8 \mathrm{mg}$ trimethoprim/l were tested for sulphonamide resistance by multipoint inoculation on to plates of Oxoid DST agar containing 4\% lysed horse blood plus $256 \mathrm{mg}$ sulphamethoxazole/1 (Roche).

Statistical analysis was as described. ${ }^{\circ}$

\section{Results}

INCIDENCE OF TRIMETHOPRIM-RESISTANT ISOLATES

A total of 3998 isolates of enterobacteria were screened for trimethoprim resistance in 1978 and 4069 in 1979 . For the surveys resistant enterobacteria were divided into $E$ coli, Klebsiella/Enterobacter sp, and 
Proteus sp. Table I shows the numbers of isolates resistant to $\geqslant 8 \mathrm{mg}$ trimethoprim/l in the two years. The small decrease in the overall incidence of resistance to this concentration of trimethoprim (from $4.8 \%$ to $2.9 \%$ ) between the two surveys was largely accounted for by a small epidemic of resistant klebsiellae during 1978 in one of the hospitals sampled. When this outbreak is taken into account there was no significant change in the overall incidence of resistant isolates. There was a small decrease in the proportion of resistant isolates classified as Proteus sp, but the proportion of resistant $E$ coli did not change between the two surveys.

TABLE I-Numbers of enterobacteria resistant to $\geqslant 8 \mathrm{mg}$ trimethoprim/l screened during fanuary to fune 1978 and 1979 (percentages of total isolates in parentheses)

\begin{tabular}{|c|c|c|c|c|c|c|c|}
\hline & & & & & & 1978 & 1979 \\
\hline $\begin{array}{l}\text { E coli } \\
\text { Klebsiella/E } \\
\text { Proteus } \mathrm{sp}\end{array}$ & $\begin{array}{l}\text { Enterobacter } \mathrm{sp} \\
\ldots \quad \ldots \\
\end{array}$ & & $\begin{array}{l}. \\
\cdots \\
\end{array}$ & $\begin{array}{l}\cdots \\
\cdots \\
\cdots\end{array}$ & $\begin{array}{l}\cdots \\
\cdots\end{array}$ & $\begin{array}{lrr}\ldots & 40 & (1.5) \\
\therefore & 115 & (17.4) \\
. & 37 & (5.8) \\
\end{array}$ & $\begin{array}{l}44(1 \cdot 5) \\
51(6 \cdot 7) \\
23(3 \cdot 4)\end{array}$ \\
\hline Total & $\ldots$ & $\ldots$ & $\ldots$ & $\ldots$ & $\ldots$ & $\ldots 192(4 \cdot 8)$ & $118(2.9)$ \\
\hline
\end{tabular}

Degrees of resistance-The figure shows the degrees of resistance to trimethoprim in each of the three groups of bacteria. There was a significant increase in the proportion of strains resistant to $\geqslant 1024 \mathrm{mg}$ trimethoprim/l between the two surveys $(p<0.001)$, which was noticeable in all three groups. All of the resistant strains isolated grew both on the routine primary isolation media and on the lysed blood medium used for sensitivity testing. None of these strains therefore required thymine for growth. ${ }^{2}$
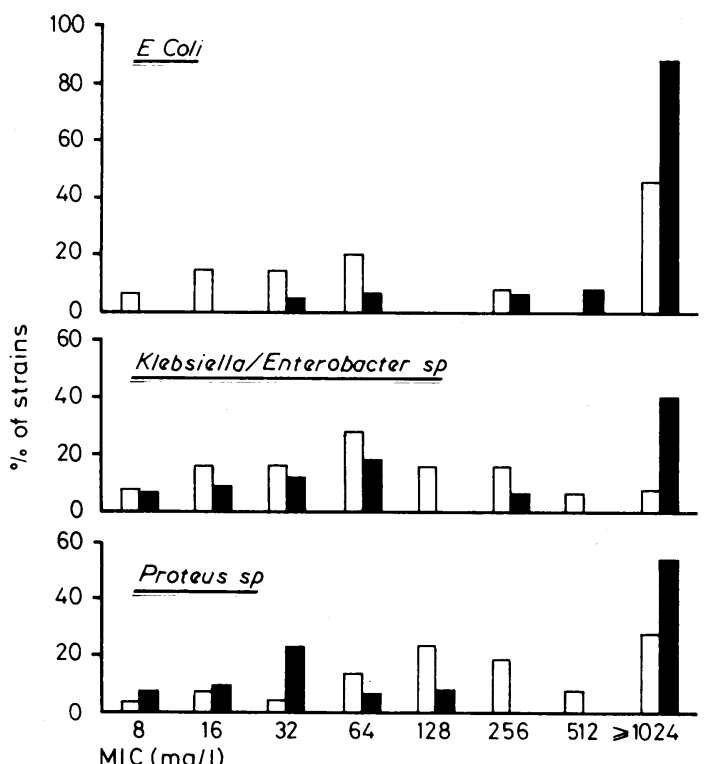

Percentages of strains of $E$ coli, Klebsiella/Enterobacter $\mathrm{sp}$ and Proteus sp resistant to trimethoprim at minimum inhibitory concentrations (MIC) of 8 to over $1024 \mathrm{mg} / \mathrm{l}$ $\square=1978$. $\square=1979$.

Transfer of resistance-All isolates resistant to $\geqslant 8 \mathrm{mg}$ trimethoprim $/ 1$ were tested for their ability to transfer resistance to a standard strain of $E$ coli. Table II gives the numbers of isolates capable of transferring resistance. In all three groups of resistant isolates the proportion owing their resistance to a transferable plasmid had increased. In each of these cases resistance to $\geqslant 1024 \mathrm{mg}$ trimethoprim/l was conferred on the new host. This increase in the proportion of resistant isolates carrying a transferable plasmid partly explains the increased incidence of high-level resistance shown in the figure. Nevertheless, there was also an increase in the proportion of strains resistant to $\geqslant 1024 \mathrm{mg}$ trimethoprim/l that failed to transfer trimethoprim resistance. In the 1978 survey nine strains $(4 \cdot 7 \%)$ failed to transfer their high-level resistance. In the 1979 survey this had risen to $27(22.9 \%)$ strains $(\mathrm{p}<0.001)$

Resistance patterns of trimethoprim $R$ plasmids-Recipient bacteria
TABLE II-Numbers of resistant isolates capable of transferring trimethoprim resistance screened during fanuary to fune 1978 and 1979 (percentages of total isolates in parentheses)

\begin{tabular}{|c|c|c|c|c|c|c|c|}
\hline & & & & & 1978 & 1979 & $p$ \\
\hline $\begin{array}{l}\text { E coli } \\
\text { Klebsiella/1 } \\
\text { Proteus sp }\end{array}$ & $\begin{array}{c}\text { Enterobacter } \mathrm{sp} \\
\ldots\end{array}$ & & $\begin{array}{l}\ldots \\
\therefore\end{array}$ & $\begin{array}{l}. \\
.\end{array}$ & $\begin{array}{c}14(35 \cdot 0) \\
3(2 \cdot 6) \\
7(18.9)\end{array}$ & $\begin{array}{r}25(56 \cdot 8) \\
11(21 \cdot 6) \\
5(21 \cdot 7)\end{array}$ & $\begin{array}{c}0.05 \\
<0.001 \\
0.95\end{array}$ \\
\hline Total & .. & .. & .. & .. & $24(12 \cdot 5)$ & $41(34 \cdot 7)$ & $<0.001$ \\
\hline
\end{tabular}

that had received trimethoprim resistance were examined for coinheritance of resistance to other antibiotics: 18 different patterns of transferable resistance were detected (table III). Two types of plasmid showed a large increase in incidence between the two surveysnamely, those conferring resistance patterns $\mathrm{TpSmSu}$ and TpSmSuKmAp TcCm (see table III). Plasmids conferring the first resistance pattern belong to the $F_{11}$ incompatibility group. ${ }^{10}$ Those conferring the second resistance pattern are similar (unpublished results) to plasmids belonging to the $M$ incompatibility group isolated from resistant Klebsiella strains responsible for an outbreak of infection in a London hospital."1 In our surveys, however, there was no obvious evidence of cross-infection: the transferable plasmids isolated were evenly distributed over the period of the surveys and were not associated with particular organisms or areas of the hospitals sampled. Where several isolates transferring the same pattern of resistance were found they invariably belonged to more than one group of bacteria.

TABLE III-Patterns of transferable resistance seen during 1978 and 1979. Figures are numbers of separate isolates

\begin{tabular}{lcclcr}
\hline Resistance pattern & 1978 & 1979 & Resistance pattern & 1978 & 1979 \\
\hline Tp & 1 & 4 & TpSmTc & 0 & 1 \\
TpSm & 5 & 4 & TpSuAp & 0 & 2 \\
TpSu & 0 & 1 & TpSmSuAp & 1 & 1 \\
TpCm & 2 & 0 & TpSuApKm & 2 & 0 \\
TpTc & 1 & 0 & TpCmApKm & 2 & 1 \\
TpKm & 2 & 2 & TpCmApTc & 1 & 0 \\
TpSmSu & 1 & 9 & TpSmSuTcCm & 0 & 1 \\
TpSmKm & 1 & 2 & TpSmSuApTcCm & 2 & 2 \\
TpSmAp & 0 & 1 & TpSmSuKmApTcCm & 3 & 10
\end{tabular}

$\mathrm{T} p=$ Trimethoprim. $\quad \mathrm{Sm}=$ Streptomycin. $\quad \mathrm{Su}=$ Sulphonamides $. \mathrm{Cm}=$ Chloram phenicol. $\quad \mathrm{Tc}=$ Tetracycline. $\mathrm{Km}=$ Kanamycin. Ap = Ampicillin.

\section{RESISTANCE TO SULPHONAMIDES}

All isolates resistant to $\geqslant 8 \mathrm{mg}$ trimethoprim/1 were also resistant to $>256 \mathrm{mg}$ sulphamethoxazole/1. Table III shows that in 1978 , $9(37.5 \%)$ out of 24 trimethoprim $\mathrm{R}$ plasmids isolated also conferred sulphonamide resistance $(4.7 \%$ of total trimethoprim-resistant isolates): in 1979 this proportion had risen to $26(63.4 \%)$ out of 41 $(22.0 \%$ of total trimethoprim-resistant isolates $)(p=0.05)$.

\section{Discussion}

In the four years before 1975 little change in the level of trimethoprim resistance among urinary tract isolates was reported. ${ }^{12} \mathrm{~A}$ further survey during 1975 and $1977^{\circ}$ disclosed a slight but significant increase in the incidence of trimethoprim resistance with, however, a very sharp increase in the proportion of this resistance attributable to transferable $\mathbf{R}$ plasmids. In contrast, a study during 1976-7 showed only a low level of plasmid-mediated trimethoprim resistance compared with chromosomal resistance. ${ }^{3}$ In our sequential surveys no overall increase in the incidence of trimethoprim resistance was detected (in fact, a slight decrease was observed), but the proportion of resistance attributable to transferable $\mathbf{R}$ plasmids almost trebled. These reported differences in the apparent prevalence and importance of $\mathbf{R}$ plasmids may well be a consequence of the properties of individual plasmids present in the particular environments sampled. Some plasmids undoubtedly disseminate themselves more widely and rapidly than others. In environments containing such plasmids the spread of plasmid 
genes conferring resistance to trimethoprim may occur more rapidly and in preference to the development of chromosomal resistance.

The overall prevalence of sulphonamide resistance in clinical isolates of enterobacteria means that a large proportion of the isolates must have been resistant to sulphonamides before exposure to trimethoprim. Furthermore, the fact that the proportion of trimethoprim $\mathrm{R}$ plasmids also carrying sulphonamide resistance had risen in 1979 to $63.4 \%$ (table III) - that is, $22.0 \%$ of total trimethoprim-resistant isolates-means that in an increasing proportion of isolates resistance to trimethoprim and sulphamethoxazole could have developed simultaneously, and no protective effect could therefore be exerted by the sulphonamide.

Another worrying feature was the increase in resistant isolates that failed to transfer their high-level trimethoprim resistance of $\geqslant 1024 \mathrm{mg} / 1\left(22.9^{\circ} \%\right.$ in 1979 compared with $4.7 \%$ in 1978). This may have been due to the spread of plasmids not capable of transferring to the standard $E$ coli recipient strain used. Alternatively it may have resulted from the transposition of genes conferring trimethoprim resistance from plasmids to the bacterial chromosome. The plasmids isolated in London that belonged to the $M$ incompatibility group carry the $\operatorname{Tn} 7$ transposon determining trimethoprim and streptomycin resistance. ${ }^{11}$ This DNA sequence may transfer with great efficiency between plasmids and the bacterial chromosome. ${ }^{13}$ Transposons of this type also occur in plasmids from strains of $E$ coli isolated outside hospitals from epidemiologically unrelated environments. ${ }^{14}$ In our surveys $13\left(54 \cdot 2^{\circ}\right)$ out of 24 plasmids isolated in 1978 and $31(75.6 \%)$ out of 41 isolated in 1979 (table III) conferred linked resistance to trimethoprim and streptomycin. These results support the possibility that spread of the $\operatorname{Tn} 7$ transposon is occurring and suggest a reason for the increase in isolates resistant to high levels of trimethoprim that failed to transfer their resistance. Further work to examine this hypothesis is in progress.

\section{References}

1 Jobanputra RS, Datta N. Trimethoprim R factors. in enterobacteria from clinical specimens. F Med Microbiol 1974;7:169-77.

${ }^{2}$ Maskell R, Okubadejo OA, Payne RH, Pead L. Human infections with thymine-requiring bacteria. $\mathcal{F}$ Med Microbiol 1977;11:33-45.

${ }^{3}$ Brumfitt W, Hamilton-Miller JMT, Grey D. Trimethoprim-resistant coliforms. Lancet 1977 ;ii :926.

4 Towner KJ, Pearson NJ, Cattell WR, O'Grady F. Chromosomal resistance to trimethoprim. Lancet $1978 ; \mathrm{i}: 1371$.

5 Brumfitt W, Franklin I, Hayek LJ, Leigh DA, Pursell R, Tsekos GR. A comparative study of the treatment of urinary infection in domiciliary practice with ampicillin, cephalexin, co-trimoxazole and trimethoprim. In: Brumfitt W, Asscher AW, eds. Urinary tract infection. London: Oxford University Press, 1973:229-39.

${ }^{6}$ Anderson JD, Lacey RW, Lewis EL, Sellin MA. Failure to demonstrate an advantage in combining sulphamethoxazole with trimethoprim in an experimental model of urinary tract infection. $\mathcal{F}$ Clin Pathol $1974 ; 27$ : 619-22.

7 Kasanen A, Anttila M, Elfving R, et al. Trimethoprim. Ann Clin Res 1978;10,suppl 22:1-39.

8 Towner KJ, Pearson NJ, Cattell WR, O'Grady F. Trimethoprim R plasmids isolated during long-term treatment of urinary tract infection with co-trimoxazole. $\mathcal{F}$ Antimicrob Chemother 1979;5:45-52.

9 Amyes SGB, Emmerson AM, Smith JT. R factor mediated trimethoprim resistance: result of two three-month clinical surveys. $f$ Clin Pathol $1978 ; 31: 850-4$.

10 Towner KJ. Classification of transferable plasmids conferring resistance to trimethoprim isolated in Great Britain. FEMS Microbiology Letters $1979 ; 5: 319-21$.

11 Datta N, Hughes VM, Nugent ME, Richards H. Plasmids and transposons and their stability and mutability in bacteria isolated during an outbreak of hospital infection. Plasmid $1979 ; 2: 182-96$.

12 Grüneberg RN. Susceptibility of urinary pathogens to various antimicrobial substances: a four-year study. F Clin Pathol 1976;29:292-5.

13 Barth PT, Datta N, Hedges RW, Grinter NJ. Transposition of a deoxyribonucleic acid sequence encoding trimethoprim and streptomycin resistances from R483 to other replicons. F Bacteriol 1976;125:800-10.

${ }^{14}$ Barth PT, Datta N. Two naturally occurring transposons indistinguishable from Tn7. 7 Gen Microbiol 1977;102:129-34.

(Accepted 29 November 1979)

\title{
Controlled trial of supervised exercise training in chronic bronchitis
}

\author{
D J M SINCLAIR, C G INGRAM
}

\section{Summary and conclusions}

In a controlled trial of exercise retraining in patients with severe chronic bronchitis, 33 subjects were followed for a mean period of $10 \cdot 3$ months. The exercise programme was supervised once a week, and daily training comprised a 12-minute walk and simple stair climbing exercises. The subjects in the exercise group showed a highly significant improvement in their walking distance, attaining a maximum increase of $24 \%$ after eight to 12 months. There was also considerable subjective improvement. The control group did not improve. No significant changes in cardiorespiratory function or muscle strength were seen.

Simple exercise rehabilitation is of benefit to patients with disabling obstructive lung disease.

Department of Clinical Measurement, Ninewells Hospital and Medical School, Dundee DD3 8EA

D J M SINCLAIR, $M B, M R C P$, senior registrar in respiratory diseases

C G INGRAM, MB, DA, senior lecturer in physiology

\section{Introduction}

Using simple unsupervised exercise, McGavin et al showed small but statistically significant improvements in the 12minute walking distance in patients with severe chronic bronchitis. ${ }^{1}$ We report here the results of a training programme which was carefully supervised in the hope of producing greater improvement in the exercise capacity of such patients.

\section{Patients and methods}

Thirty-three patients were studied. All had been heavy cigarette smokers and had symptoms of chronic bronchitis in accordance with the Medical Research Council definition. ${ }^{2}$ Patients with symptomatic ischaemic heart disease, hypertension, peripheral vascular disease, and neurological or musculoskeletal problems were excluded. When they had recovered from the acute exacerbation those in hospital started daily 12 -minute walking distance assessments ${ }^{3}$ while the others were admitted to familiarise them with the exercise regimen. Immediately before discharge, when they were considered to be in an optimal condition clinically, pulmonary function and exercise capacity were assessed.

Forced expiratory volume in one second $\left(\mathrm{FEV}_{1}\right)$ and forced vital 